\title{
Segregation studies and linkage analysis of Atlantic salmon microsatellites using haploid genetics
}

\author{
AUDUN SLETTAN*, INGRID OLSAKER \& ØYSTEIN LIE \\ Department of Morphology, Genetics and Aquatic Biology, Norwegian College of Veterinary Medicine, PO Box 8146 \\ Dep., N-0033 Oslo, Norway
}

\begin{abstract}
A genetic marker map of Atlantic salmon would facilitate the identification of loci influencing economically important traits. In the present paper we describe five new Atlantic salmon microsatellites. Segregation studies and linkage analysis of these and previously published microsatellites were carried out in pedigrees consisting of diploid dams and haploid gynogenetic offspring. We confirm earlier reports that salmon microsatellites tend to have a higher number of repeat units than those of mammals. Linkage analysis revealed that three microsatellites belong to a linkage group spanning $\approx 50 \mathrm{cM}$ of the genome, whereas the remaining 10 markers seem to be unlinked.
\end{abstract}

Keywords: Atlantic salmon, genetic mapping, haploid gynogenesis, microsatellites, Salmo salar.

\section{Introduction}

The economic importance of salmonids together with the fact that they occupy a critical position in understanding vertebrate genome evolution has resulted in many genetic studies in salmonids. Many of these involve analyses of stocks and pedigrees using electrophoretic techniques on polymorphic proteins. These studies have provided markers useful for building genetic maps and a composite salmonid linkage map has been constructed by combining linkage analyses from different salmonid species (Salvelinus, Salmo and Onchorynchus) (May \& Johnson, 1990). This map consists of over 50 loci in 18 classical linkage groups and six pseudolinkage groups. The latter linkage groups are based on the recombination fraction exceeding 50 per cent observed between duplicated loci residing on different synteny groups in backcross offspring from male $F_{1}$ hybrids (Davisson et al., 1973). Wright and coworkers (1983) explained pseudolinkage by means of multivalent pairing in males among metacentric chromosomes having arms homologous with acrocentric chromosomes. However, pairing in females is strictly bivalent. Although most data show that salmonids have completed their diploidization

*Correspondence. E-mail: audun.slettan@veths.no process after the recent tetraploidization, the pseudolinkage phenomenon reflects probably some residual tetrasomic inheritance (Wright et al., 1983).

The polymorphism of allozyme systems is generally low. More recently other classes of markers based on DNA polymorphism in the salmonid genome have been reported, for instance multilocus and single locus (SLP) minisatellite markers (Taggart \& Ferguson, 1990a,b; Prodöhl et al., 1994). Minisatellites have a much higher degree of polymorphism than the protein markers and the SLPs are especially valuable tools in population genetic studies and genetic mapping analyses. During recent years another class of DNA markers, the microsatellites, which also display polymorphism as a variable number of repeats of a short DNA motif, has been reported in salmonid fishes (Franck et al., 1991; Estoup et al., 1993; Slettan et al., 1993, 1995a,b, 1996; McConnell et al., 1995). The high degree of polymorphism displayed, the relatively even distribution in the genome, the ease with which they can be analysed by the PCR method and the fact that the markers can readily be adopted and used by other research groups (PCR primer information), has made microsatellites the markers of choice in genetic linkage studies of eukaryotic species. Also in population studies this marker type is very suitable and has, for instance, been used to 
discriminate genetically populations of Brown trout (Estoup et al., 1993) and Atlantic salmon (McConnell et al., 1995).

Genetic mapping studies are usually performed in two or three generation full- or half-sib pedigrees. In a recent paper (Lie et al., 1994) we described a strategy for genetic mapping of Atlantic salmon using haploid gynogenetic pedigrees, an approach that in many ways is the female counterpart of single sperm typing. An advantage of this strategy is that because each haploid offspring represents one single meiotic event in the mother, the structure and analysis of the family material is made easier.

In the present paper we report the characterization of five new Atlantic salmon microsatellites and the genetic analyses of these as well as of previously published microsatellite markers (Slettan et al., 1995a,b, 1996) in haploid individuals produced by haploid gynogenesis of Atlantic salmon.

\section{Materials and methods}

\section{Biological material}

The family material used in the segregation analyses of microsatellites was haploid offspring from unrelated females, produced by haploid gynogenesis: $\approx 2000$ eggs from 20 females were fertilized with $\mathrm{X}$-rayed $(100 \mathrm{krad})$ and hence inactivated sperm, and allowed to develop at $8^{\circ} \mathrm{C}$. Haploid embryos will die before or at hatching, so the eggs were collected 300 day-degrees after fertilization. For a more detailed description of the procedure see Refstie et al. (1982). Single embryos, unhatched, were put in Eppendorf tubes, frozen in a dry ice/ethanol bath and stored at $-70^{\circ} \mathrm{C}$ until the DNA was extracted.

The population material on which the microsatellites were analysed for allele numbers, sizes and frequencies consisted of 30 unrelated Atlantic salmon individuals from the Norwegian breeding stock. This stock is a result of crossbreeding of $\approx 20$ wild strains from Norwegian rivers. Muscle tissue was collected and stored at $-70^{\circ} \mathrm{C}$ until the DNA was extracted.

\section{DNA isolation}

Standard procedures for isolation of DNA from the muscle tissue were followed. The DNA from the haploid embryos was isolated as follows. The nonhatched embryos were placed in an Eppendorf tube and $300 \mu \mathrm{L} 1 \times \mathrm{RSB}$ buffer (10 mM Tris pH 7.4, $10 \mathrm{~mm} \mathrm{NaCl}, 25 \mathrm{~mm}$ EDTA) were added. The soma was punctured with a syringe, $38 \mu \mathrm{L} 10$ per cent SDS and $15 \mu \mathrm{L}$ proteinase $\mathrm{K}(20 \mathrm{mg} / \mathrm{mL})$ were added before incubation overnight at $37^{\circ} \mathrm{C}$ with gentle rocking. Ten $\mu \mathrm{L}$ proteinase $\mathrm{K}$ was then added and the incubation continued for $1 \mathrm{~h}$. The samples were extracted twice with phenol/chloroform/isoamyl alcohol (24:24:1), and once with chloroform before the DNA was precipitated with ethanol. The DNA was washed twice with 70 per cent EtOH and resuspended in $300 \mu \mathrm{L}$ TE buffer containing $5 \mu \mathrm{g} / \mathrm{mL}$ RNase. The DNA was stored at $-20^{\circ} \mathrm{C}$.

\section{Isolation of microsatellite markers}

An Atlantic salmon genomic DNA library, containing size-selected Sau3AI, RsaI, HaeIII and SspI fragments $(200-500 \mathrm{bp})$ in pBLUESCRIPT, enriched for clones containing $(\mathrm{GT})_{n}$ repeats, was constructed according to the procedure described by Ostrander et al. (1992). An end-labelled (GT) $)_{10}$ probe was used to screen clones from this library and from a sizeselected (100-500 bp, Sau3AI) genomic library (Slettan et al., 1993). Positive clones were subsequently cultured, the plasmid DNA isolated using the Qiagen plasmid mini kit (Qiagen) and the microsatellite sequences revealed using a semiautomated DNA sequencing machine (ALF, Pharmacia). These sequences have been submitted to the EMBL data bank (Table 1). PCR primers flanking the repeat core were designed (Table 2).

\section{PCR conditions}

Studies of the population material The reactions took place in a total volume of $26 \mu \mathrm{L}$ containing $\approx 50 \mathrm{ng}$ Atlantic salmon DNA, $1.5 \mathrm{~mm} \mathrm{MgCl}_{2}$, $50 \mathrm{~mm} \mathrm{KCl,} 10 \mathrm{~mm}$ Tris- $\mathrm{HCl}$ pH 8.3, $200 \mu \mathrm{M}$ dNTP, $10 \mathrm{pmol}$ of each unlabelled primer, $0.1 \mathrm{pmol}$ labelled primer, $1 \mathrm{U}$ Ampli-Taq DNA polymerase (PerkinElmer-Cetus). The upper primer was end-labelled with $\left[\gamma^{32} \mathrm{P}\right]$ ATP (Amersham) with T4 polynucleotide kinase (Boehringer M.). Amplification was performed using the Gene Amp PCR system 9600 from Perkin-Elmer-Cetus. Temperature cycling conditions were as follows: first an initial denaturation step at $94^{\circ} \mathrm{C}, 3 \mathrm{~min}$; then 32 cycles of: (i) denaturation at $94^{\circ} \mathrm{C}, 40 \mathrm{~s}$; (ii) annealing at the temperatures given in Table $1,40 \mathrm{~s}$; and (iii) extension at $72^{\circ} \mathrm{C}$ for $40 \mathrm{~s}$. The final extension was at $72^{\circ} \mathrm{C}$ for $7 \mathrm{~min}$.

Inheritance analyses for linkage studies Generally the same PCR conditions and concentrations were applied as above, except that all markers apart from SSOSL446A and $B$ were amplified with unlabelled 
Table 1 Details of the Atlantic salmon microsatellites included in this study

\begin{tabular}{|c|c|c|c|c|c|c|c|}
\hline Locus & $\begin{array}{l}\text { Accession } \\
\text { number }\end{array}$ & $\begin{array}{l}\text { PCR product } \\
\text { length }(\mathrm{bp})^{a}\end{array}$ & $\begin{array}{l}\text { Observed } \\
\text { alleles }\end{array}$ & $\mathrm{PIC}^{b}$ & $\begin{array}{l}\text { Annealing } \\
\text { temp. }\left({ }^{\circ} \mathrm{C}\right)\end{array}$ & $\begin{array}{c}\text { Repeat } \\
\text { sequence }^{c}\end{array}$ & Reference \\
\hline SSOSL20 & X92473 & 120 & 8 & 0.74 & 58 & $(\mathrm{CA})_{24}$ & This work \\
\hline SSOSL34 & Z69643 & 111 & 7 & 0.66 & 54 & $(G T)_{18}$ & This work \\
\hline SSOSL32 & Z69642 & 163 & 7 & 0.82 & 55 & $-^{d}$ & This work \\
\hline $\operatorname{SSOSL} 446 A+B^{e}$ & Z69644 & 132 & 11 & $-f$ & 56 & $(\mathrm{AC})_{25}$ & This work \\
\hline SSOSL 456 & Z69645 & 177 & 1 & 0.00 & 58 & $(\mathrm{AC})_{12} \mathrm{AG}(\mathrm{AC})_{10}$ & This work \\
\hline SSOSL25 & Z48581 & 159 & 5 & 0.67 & 58 & $(\mathrm{TG})_{32}$ & Slettan et al. (1995a) \\
\hline SSOSL85 & Z48596 & 194 & 8 & 0.80 & 55 & $(G T)_{22}$ & Slettan et al. (1995a) \\
\hline SSOSL311 & Z48597 & 166 & 8 & 0.71 & 55 & $(\mathrm{TG})_{38}$ & Slettan et al. (1995a) \\
\hline SSOSL417 & Z48598 & 187 & 6 & 0.74 & 53 & $(\mathrm{TG})_{25}$ & Slettan et al. (1995a) \\
\hline SSOSL436 & Z49118 & 150 & 10 & 0.76 & 54 & $(\mathrm{TG})_{41}$ & Slettan et al. (1995b) \\
\hline SSOSL 438 & Z49134 & 140 & 6 & 0.76 & 50 & $(\mathrm{AC})_{26} \mathrm{AT}(\mathrm{AC})_{6}$ & Slettan et al. (1996) \\
\hline SSOSL439 & Z49996 & 154 & 7 & 0.73 & 56 & $(\mathrm{AC})_{30}$ & Slettan et al. (1996) \\
\hline SSOSL 444 & Z49997 & 135 & 5 & 0.48 & 58 & $(\mathrm{AC})_{41}$ & Slettan et al. (1996) \\
\hline
\end{tabular}

${ }^{a}$ Length of the PCR product of the original isolated clone; ${ }^{b}$ the polymorphism information content was estimated according to Botstein et al. (1980); ${ }^{c}$ repeat sequence of the original clone; ${ }^{d}$ the repeat core is very long and we were not able to sequence through it; ${ }^{e,}$ the length of the alleles of the two loci SSOSL446A and SSOSL $446 B$ overlap.

Comprehensive segregation studies of many pedigrees are necessary to determine which alleles correspond to which locus. For the same reason no PIC value has been calculated.

Table 2 Nucleotide sequence of PCR primers for Atlantic salmon microsatellites

\begin{tabular}{ll}
\hline Microsatellite & Nucleotide sequence \\
\hline SSOSL20-U & 5'-TCA CAA GAG TGC ATC AGC TAC AG-3' \\
SSOSL20-L & 5'-GGA GAG GAG GAG GGG AGA GAA TA-3' \\
SSOSL32-U & 5'-CTG TAT ACT ATG GTG GTG GCT-3' \\
SSOSL32-L & 5'-TTA TGT CAG ACC AGG TGG CTA-3' \\
SSOSL34-U & 5'-CTT TAG TCT GCC TGT CTT CGT AT-3' \\
SSOSL34-L & 5'-ATT TAA TCT TCT TTC TGA CAC AA-3' \\
SSOSL446-U & 5'-GGA TAA AAC AAC AGG CTC AGT TCA-3' \\
SSOSL446-L & 5'-GCT GGA GCA GGG ACA TGT ATT-3' \\
SSOSL456-U & 5'-CTT CCC AGG AGT CAT CAT AAA TCT-3' \\
SSOSL456-L & 5'-TAA ACC CCA CTG CTT GTT GAG TGT-3' \\
\hline
\end{tabular}

primers and sized on agarose gels. Because of the lack of radioactive labelled primers, the number of cycles in the PCR was raised to 39. SSOSL446A and $B$ were analysed on polyacrylamide gels as described below.

\section{Genotyping}

Radioactively labelled PCR products were mixed 50:50 with formamide loading dye and analysed on 6 or 8 per cent acrylamide, $8 \mathrm{M}$ urea gels. The gels were dried and autoradiographed for 6-24 h. Allele sizes were determined by comparison with an M13 DNA sequence ladder and/or by including the PCR product from the original sequenced clone to provide a control allele of known size. The polymorphism information content (PIC) of the microsatellites was estimated according to Botstein et al. (1980). The alleles were named according to the length of the PCR product. For example, the allele of SSOSL20 with the length of $139 \mathrm{bp}$ was named SSOSL20-139.

The unlabelled PCR products from the haploid individuals were analysed on 3 or 4 per cent Meta- 
Phor agarose gels (FMC) in $1 \times$ TBE buffer with $0.5 \mu \mathrm{g} / \mathrm{mL}$ ethidium bromide. The gels were examined on a UV transilluminator and photographed. Linkage analysis was performed using the MAPMAKER program (Lander et al., 1987). The Kosambi mapping function was used because of the strong interference exhibited in salmonid meiosis (Thorgaard et al., 1983).

\section{Results}

Approximately 2000 eggs from each of the 20 females were 'pseudofertilized' by irradiated, inactivated sperm. By the time of collection' of haploid embryos, the survival of eggs varied from 2 to 40 per cent among the 20 groups, with a mean of 13 per cent.

During the segregation analyses of microsatellite markers for linkage studies no genetic contribution from the irradiated sperm could be detected: only fragments corresponding to the alleles in the mother were found in the haploid offspring. The possibility that more than the maternal haploid genome could be present in some embryos was examined by analysing the segregation data: 99.4 per cent of the PCRs on the haploid embryos produced either one or the other maternal band whereas the remaining 0.6 per cent of the reactions produced both maternal bands. One haploid individual displayed both maternal fragments in three of eight markers, whereas in the rest of the individuals with two maternal bands this was observed for only one marker.

The concentration of DNA isolated from the haploids was estimated by UV-spectrophotometry. There was still some protein contamination in the samples making the quantification inaccurate, but the amount of DNA isolated from one haploid embryo was $\approx 350 \mu \mathrm{g}$. Analysis of the DNA on 1 per cent agarose gels revealed that the DNA was partially degraded. However, this degradation did not have any impact on the PCR analysis. The size of the PCR products in the haploid offspring always corresponded to the maternal fragments, and only seven haploid individuals of 201 failed to give products on more than one microsatellite locus.

\section{Genetic variation in the microsatellites}

Four of the five microsatellites described in this paper and the previously published microsatellites show a high degree of polymorphism and repeat sequences that are generally longer than in mammals, as was also described in an earlier publi- cation on Atlantic salmon microsatellites (Slettan et al., 1993). Information about the new microsatellites together with the other markers that were included in the linkage analysis is given in Table 1 . The high polymorphism information content (PIC) shows that the salmon microsatellites are very suitable as markers for genetic mapping.

In spite of a relatively long repeat sequence $\left[(\mathrm{AC})_{12} \mathrm{AG}(\mathrm{AC})_{10}\right]$ one marker, SSOSL456, showed no length variation in the test panel of 30 unrelated fishes, which also included the dams of the family material used for linkage analysis.

For one of the microsatellites, SSOSL34, the alleles could be grouped into two classes according to length. Two alleles were rather short, $111 \mathrm{bp}$ and $115 \mathrm{bp}$, whereas the remaining six varied between 177 and $211 \mathrm{bp}$. The difference in length between the two classes of alleles might be caused by variation in the number of GT-repeats or by deletion of a region flanking the dinucleotide repeat in the 'short' alleles. To examine these possibilities, the SSOSL34-111 and SSOSL34-179 alleles of dam 7813 were cloned into the pCRII vector using the TA Cloning kit (Invitrogen). The inserts were sequenced and revealed that the $179 \mathrm{bp}$ allele contains 52 repeats of the GT-dinucleotide, whereas the $111 \mathrm{bp}$ allele contains 18 repeats. The flanking sequences were identical.

All microsatellite markers showed a codominant segregation pattern in the haploid family material. All except two of the loci (SSOSL32 and SSOSL446) displayed two bands in the heterozygous dam, and one or the other allele in each of the haploid offspring. SSOSL32 showed a constant PCR fragment of 70 base pairs in all individuals in the test population in addition to alleles of $110-170 \mathrm{bp}$. This constant band is longer than expected primer-primer dimers and might be the result of deletion of the dinucleotide repeat core at a duplicated locus.

\section{Segregation and linkage analysis}

PCR amplification with the primers designed for the SSOSL446 sequence resulted in products from two distinct loci. Thus, individuals in the test population heterozygous for both loci show four bands in the PCR. When haploid offspring from a double heterozygote were analysed, two bands were displayed in each haploid individual (Fig. 1). The alleles of each locus are distributed in a Mendelian segregation pattern compatible with disomic inheritance, indicating duplicated loci that have been diploidized. The two loci have been named SSOSL446A and SSOSL 446B. 
All microsatellite loci segregated according to simple Mendelian inheritance laws in two pedigrees (7813 and 7479). However, one marker, SSOSL20, showed segregation distortion in haploid offspring from a third dam (8321). The two maternal alleles, SSOSL20-139 and SSOSL20-174, segregated to give

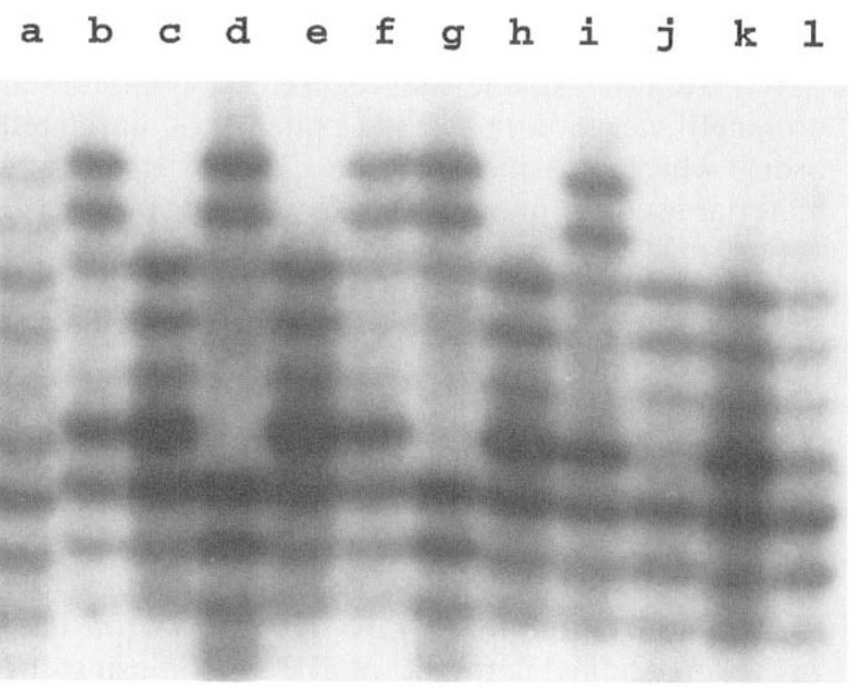

Fig. 1 Segregation of SSOSL446A (upper alleles) and SSOSL 446B (lower alleles) in 11 haploid offspring (lanes b-l) of a doubly heterozygous Atlantic salmon dam (lane a). a ratio of 30:59. After Bonferroni correction to allow for multiple testing (Altman, 1991, pp. 210-212) the observed segregation is still significantly different from the expected 1:1 ratio at the 1 per cent level. Dam 7813 carries the same SSOSL20 alleles as 8321, but here the ratio in the offspring $(45: 31)$ was not significantly different from even proportions. The SSOSL20 alleles of dam 7479, SSOSL20-139 and SSOSL20-207, also segregated in concordance with simple Mendelian laws (41:39).

For genetic mapping of the microsatellites, the segregation of the markers was followed in family material consisting of two Atlantic salmon females (7813 and 7479) with 102 and 99 haploid offspring each. Marker SSOSL456 was not informative in this family material and was therefore not included in this analysis. The other 13 markers were informative in either one or both pedigrees. PCR products were sized on agarose gels or polyacrylamide gels (SSOSL446A and $B$ ). The fact that each haploid individual produces only one band facilitated the genotyping. An example of segregation of two microsatellites in some of the haploid offspring of one dam is shown in Fig. 2.

Computer-assisted analysis revealed that three of the markers belong to a linkage group spanning 50.3 Kosambi centimorgans (Table 3). The data did not

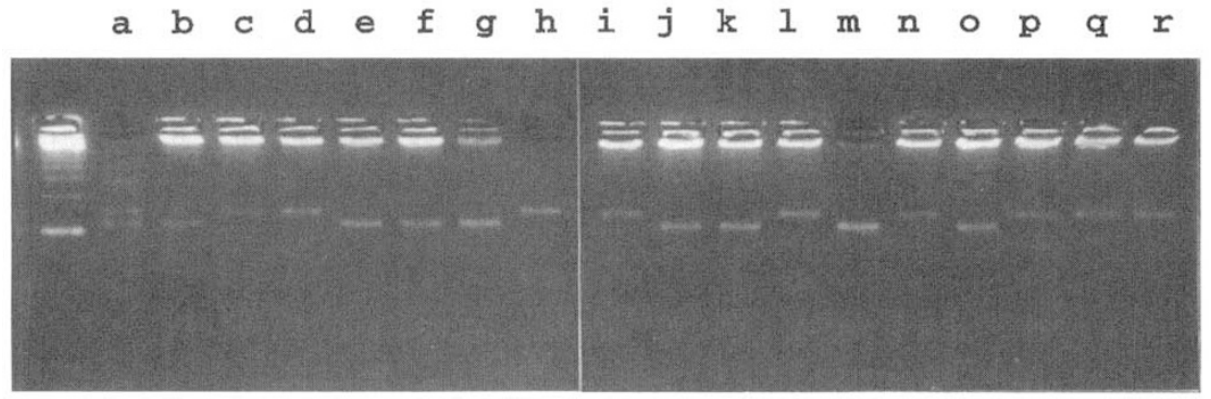

(a)

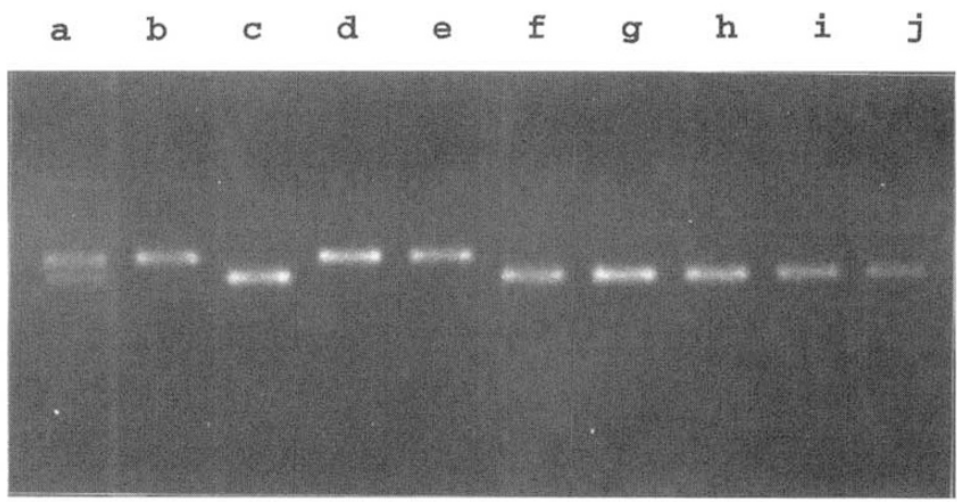

(b)
Fig. 2 Segregation of SSOSL2O (Fig. 1a) and SSOSL25 (Fig. 1b) in haploid offspring (lanes $b-r$ ) of dam 7813 (lane a). 
Table 3 Two-point linkage study (showing a lod score higher than 3.0) of the microsatellites in the Atlantic salmon haploid family material

\begin{tabular}{lccc}
\hline Microsatellites & $\begin{array}{c}\text { Recombination } \\
\text { fraction }\end{array}$ & Lod score & $\mathrm{cM}$ \\
\hline SSOSL34-SSOSL32 & 0.27 & 4.32 & 30.45 \\
SSOSL34-SSOSL85 & 0.26 & 9.13 & 28.45 \\
SSOSL85-SSOSL32 & 0.20 & 7.75 & 21.44 \\
\hline
\end{tabular}

give significant support (i.e. a lod score greater that $3)$ to the hypothesis that any of the other microsatellites were linked. Using multipoint linkage analysis, the order of the three linked markers was found to be SSOSL32-SSOSL85-SSOSL34. This sequence is significantly ( $>1000: 1)$ more likely than either of the other two possible orders.

\section{Discussion}

The microsatellite sequences described here confirm the earlier observation that microsatellites in Atlantic salmon tend to be longer than those in higher vertebrates (Slettan et al., 1993). The same has been observed in Atlantic cod (Gadus morhua) and rainbow trout (Onchorynchus mykiss) (Brooker et al., 1994). The reason for this phenomenon is unknown. A substantial number of studies suggest that microsatellite mutations may be biased in favour of longer, rather than shorter, allele length (see, e.g., Rubinsztein et al., 1995). Mutations in the mechanisms involved in microsatellite evolution may therefore be a possible explanation for the longer repeat stretches observed in salmon compared to mammals. Strand slippage by DNA polymerase is thought to be the major mechanism of microsatellite evolution.

Given the relatively high degree of polymorphism observed in the microsatellites, the lack of polymorphism of SSOSL456 in our test population is somewhat surprising. The test population was collected from the Norwegian salmon breeding pool, which is descended from several crossbreeds between fish from a total of 18 wild stocks from Norwegian rivers and is therefore expected to exhibit a high degree of genetic variability. The fixation of this microsatellite, which has $12+10$ GT repeats and would therefore be expected to show a high degree of polymorphism (Weber, 1990) might have occurred by selection of specific alleles of linked genes through the breeding programmes and/or in the wild. This marker should be tested in Atlantic salmon populations from other regions of Europe, and from America and Asia to see whether the degree of polymorphism is higher or whether the marker is fixed, but with other alleles.

The use of haploid gynogenetic individuals is a valuable supplement to linkage analysis using traditional family material. Each individual represents one meiotic event in the mother, and this process is in many ways the female counterpart of single sperm typing. Approximately $350 \mu \mathrm{g}$ of DNA was extracted from each of the haploid embryos used in this study. As $50 \mathrm{ng}$ of DNA is used in each PCR, this provides enough material for $\approx 7000$ PCR tests of the same individual, which is considerably larger than the number of tests possible on single sperm cells. Thus, enough DNA is available from each embryo to provide the basis for the construction of a genetic marker map of Atlantic salmon.

This kind of family material will give a female linkage map. It is a well-established fact that recombination frequencies differ between the sexes in many animals, so also in fish (Johnson et al., 1987). To produce a combined genetic map or a malespecific map, it will therefore be necessary to use typing of traditional family material, single sperm typing or haploid androgenesis in addition to analysis of haploid gynogenetic material.

Segregation distortion of SSOSL20 alleles was observed in the offspring of dam 8321. The two alleles differ by $35 \mathrm{bp}$. Hence, the possibility that the observed segregation distortion is a result of mistyping of the genotypes is ruled out. A significant excess of haploids inherited the allele SSOSL20-174 rather than the SSOSL20-139 allele. This indicates that the SSOSL20 locus is linked to one or more genes that in this individual elicit a selective advantage or disadvantage in a certain proportion of the offspring. If this gene is in heterozygous form in fish 8321 with one nonlethal and one lethal allele, the smallest group of offspring represents the recombinants resulting from crossover events between the gene and the microsatellite locus. However, because the effect of the allele is unknown (it may not be fully lethal), calculation of map distances is not possible. No significant segregation distortion is seen in the sibs from dam 7813, which carry the same SSOSL20 loci as 8321 . This suggests that the allele causing lethality and the SSOSL20-139 allele do not segregate jointly. Although linkage between a lethal mutation and a microsatellite locus will influence the segregation proportions of the marker alleles, the recombination frequency estimates between this marker and other linked markers will not be disturbed. Consequently, alleles with a lethal or sublethal effect present in the parent of haploid material will not complicate the calculations involved in the 
construction of a linkage map. For a more detailed discussion of this, see Lie et al. (1994).

Salmonids have almost completed the diploidization process after a fairly recent tetraploidization event (Ohno et al., 1969). The many duplicated loci residing on different chromosomes, and the observed pseudolinkage between duplicated loci in males (Wright et al., 1983; Johnson et al., 1987), reflect this genome duplication. The primer sets designed for two of the microsatellites described here hybridize to more than one locus. The primer set for SSOSL446 recognizes two loci, SSOSL446A and SSOSL446B, which show a disomic segregation pattern and do not seem to be linked. It is likely that these loci reside on different chromosomes. PCR analyses of SSOSL32 in the test population revealed that a fragment of $70 \mathrm{bp}$ was produced in all individuals in addition to the polymorphic alleles in the $110-170$ bp range. The nonpolymorphic locus may be a homologous locus of the polymorphic SSOSL 32 that has lost most of the dinucleotide repeat sequence. Cloning and sequencing of this fragment might confirm this. Prodöhl et al. (1994) and Taggart et al. (1995) have studied the segregation pattern of single-locus minisatellite probes (SLP) in brown trout and Atlantic salmon, respectively. They report examples of duplicated SLP loci probably located on different chromosomes. Further studies of microsatellites, SLPs and other noncoding and apparently nonselected DNA sequences should give more information on the evolutionary process from a tetraploid to a diploid genome.

All microsatellites included in this work except SSOSL456 show a high degree of polymorphism in the test population. They are also informative, heterozygous, in either one or both of the dams in the haploid family material. They could therefore be used in the construction of a genetic marker map of the Atlantic salmon genome. Of the 13 markers, three were assigned to a single linkage group spanning $\approx 50$ centimorgans of the genome. None of the other markers appeared to be linked.

The new linkage group described in this paper has been named no. 19 , in accordance with the numbering of salmonid classical linkage groups and the nomenclature introduced by May \& Johnson (1990). To assign this new linkage group to the existing map it will be necessary to type our markers using the material on which the enzyme markers have been applied or to develop and analyse DNA markers for some of these enzyme genes in our material. It is possible to generate diploid gynogenetic family material of salmonids. Such families can be utilized to map the genetic distance between the markers and the centromere and thus orientate the linkage groups relative to the centromere and other linkage groups residing on the same chromosome. Furthermore, other highly polymorphic salmonid DNA markers should also be placed on the genetic map. For instance Prodöhl et al. (1994) and Taggart et al. (1995) have reported close linkage between two SLP minisatellites to be conserved in brown trout and Atlantic salmon.

The development of a physical map (for instance assigning markers to specific chromosomes by FISH) will make it easier to fill in gaps in a genetic map. However, karyotyping of salmonids by conventional banding techniques is very difficult. New techniques, such as direct in situ single-copy PCR (DISC-PCR) (Troyer et al., 1994) on metaphase chromosome preparations with marker primer sets should make it possible to construct a battery of chromosomespecific markers and thus overcome the present difficulties in chromosome discrimination.

The microsatellites presented here constitute a set of highly informative genetic markers suitable for both genetic mapping and population genetic studies. These markers and additional isolated micro- and minisatellites from salmonids should be employed to construct a genetic linkage map for Atlantic salmon and salmonids.

\section{Acknowledgements}

The authors would like to thank Ms Birthe Mikkelsen for expert technical assistance. This work was supported by grants from the Research Council of Norway.

\section{References}

Altman, D. G. 1991. Practical Statistics for Medical Research, Chapman and Hall, London.

BOTSTEIN, D., WHITE, R. L., SKOLNICK, M. AND DAVIS, R. W. 1980. Construction of a genetic linkage map in man using restriction fragment length polymorphism. Am. J. Hum. Genet., 32, 314-331

BROOKER, A. L., COOK, D., BENTZEN, P., WRIGHT, J. M. AND DOYLE, R. W. 1994. Organization of microsatellites differs between mammals and coldwater teleost fishes. Can. J. Fish Aquat. Sci., 51, 1959-1966.

DAVISSON, M. T., WRIGHT, J. E. AND ATHERTON, L. M. 1973. Cytogenetic analysis of pseudolinkage of $L D H$ loci in the teleost genus Salvelinus, Genetics, 73, 645-658.

ESTOUP, A., PRESA, P., KRIEG, F., VAIMAN, D. AND GUYOMARD, R. 1993. (CT) $)_{n}$ and $(\mathrm{GT})_{n}$ microsatellites: a new class of genetic markers for Salmo trutta L. (brown trout). Heredity, 71, 488-496. 
FRANCK, J. P., HARRIS, A., BENTZEN, P., DENOVAN-WRIGHT, E. M. AND WRIGHT, J. 1991. Organization and evolution of satellite, minisatellite and microsatellite DNAs in teleost fishes. Oxford Surv. Eukaryotic Genes, 7, 51-82.

JOHNSON, K. R., WRIGHT, J. E. AND MAY, B. 1987. Linkage relationships reflecting ancestral tetraploidy in salmonid fish. Genetics, 116, 579-591.

LANDER, E., GREEN, P., ABRAHAMSON, J., BARLOW, A., DALEY, M., LINCOLN, S. AND NEWBURG, L. 1987. MAPMAKER: An interactive computer package for constructing primary genetic linkage maps of experimental and natural populations. Genomics, 1, 174-181.

LIE, Ø., SLETTAN, A., LiNGAAS, F., OlSAKER, 1., HORDVIK, I. AND REFSTIE, T. 1994. Haploid gynogenesis: A powerful strategy for linkage analysis in fish. Anim. Biotech., 5, 33-45.

MAY, B. AND JOHNSON, K. R. 1990. Composite linkage map of salmonid fishes (Salvelinus, Salmo, Onchorynchus). In: O'Brien, S. J. (ed.) Genetic Maps: Locus Maps of Complex Genomes. Book 4, Nonhuman Vertebrates, pp. 151-159. Cold Spring Harbor Laboratories, Cold Spring Harbor, NY.

McCONNELl, S., O'REILly, P., HAMILTON, L., WRIGHT, J. AND BENTZEN, P. 1995. Polymorphic microsatellite loci from Atlantic salmon (Salmo salar): genetic differentiation of North American and European populations. Can.J. Fish. Aquat. Sci., 52, 1863-1872.

OHNO, S., MURAMOTO, J.; KLEIN, J. AND ATKIN, N. R. 1969. Diploid-tetraploid relationship in clupleoid and salmonid fish. In: Darlington, C. D. and Lewis, K. R. (eds) Chromosomes Today, vol. II, pp. 139-147. Oliver and Boyd, Edinburgh.

OSTRANDER, E. A., JONG, P. M., RINE, J. AND DUYK, G. 1992. Construction of small-insert genomic DNA libraries highly enriched for microsatellite repeat sequences. Proc. Natl. Acad. Sci. U.S.A., 89, 3419-3423.

PRODÖHL, P. A., TAGGART, J. B. AND FERGUSON, A. 1994. Single locus inheritance and joint segregation analysis of minisatellite (VNTR) DNA loci in brown trout (Salmo trutta L.). Heredity, 73, 556-566.

REFSTIE, T., sTOSs, J. AND DONALDSON, E. M. 1982. Production of all-female coho salmon (Oncorynchus kisutch) by diploid gynogenesis using irradiated sperm and cold shocks. Aquaculture, 29, 67-82.

RUBINSZTEIN, D. C., AMOS, W., LEGGO, J., GOODBURN, S., JAIN, S., L1, S. H. ET AL. 1995. Microsatellite evolution - evidence for directionality and variation in rate between species. Nature Genetics, 10, 337-343.

SLETTAN, A., OLSAKER, I. AND LIE, ø. 1993. Isolation and characterization of variable $(\mathrm{GT})_{n}$ repetitive sequences from Atlantic salmon, Salmo salar L. Anim. Genet., 24, 195-197.

SLeTTAN, A., OlSAKER, 1. AND LIE, $\varnothing$. 1995a. Atlantic salmon, Salmo salar, microsatellites at the SSOSL25, SSOSL85, SSOSL311, SSOSL417 loci. Anim. Genet., 26, 281-282.

SLETTAN, A., OlSAKER, I. AND LiE, $\varnothing$. 1995b. A polymorphic dinucleotide repeat microsatellite in Atlantic salmon, Salmo salar (SSOSL436). Anim. Genet., 26, 368.

SLeTTAN, A., OlsAKER, 1. AND LIE, $\varnothing$. 1996. Polymorphic Atlantic salmon (Salmo salar L.) microsatellites at the SSOSL438, SSOSL439 and SSOSL444 loci. Anim. Genet., 27, 57-58.

TAGGART, J. B. AND FERGUSON, A. 1990a. Minisatellite DNA fingerprints of salmonid fishes. Anim. Genet., 21, 377-389.

TAGGART, J. B. AND FERGUSON, A. 1990b. Hypervariable minisatellite DNA single locus probes for the Atlantic salmon, Salmo salar L. J. Fish Biol, , 37, 991-993.

TAGgarT, J. B., PRODÖHL, P. A. AND FERGuSON, A. 1995. Genetic markers for Atlantic salmon (Salmo salar L.): single locus inheritance and joint segregation analyses of minisatellitee (VNTR) DNA loci. Anim. Genet., 26, 13-20.

THORGAARD, G. H., ALLENDORF, F. W. AND KNUDSEN, K. L. 1983. Gene-centromere mapping in rainbow trout: high interference over long map distances. Genetics, 103, 771-783.

TROYER, D. L., GOAD, D. W., XIE, H., ROHRER, G. A., AlEXANDER, L. J. AND BEATTIE, C. W. 1994. Use of direct in situ single-copy (DISC) PCR to physically map five porcine microsatellites. Cytogenet. Cell Genet., 67, 199-204.

WEBER, J. L. 1990. Informativeness of human (dC-dA) $(\mathrm{dG} \cdot \mathrm{dT})_{n}$ polymorphisms. Genomics, 7, 524-530.

WRIGHT, J. E., JOHNSON, K., HOLLISTER, A. AND MAY, B. 1983. Meiotic models to explain classical linkage, pseudolinkage and chromosome pairing in tetraploid derivative salmonid genomes. In: Rattazzi, M. C., Scandalios, J. G. and Whitt, G. S. (eds) Isozymes: Current Topics in Biological and Medical Research, vol. 10, pp. 239-260. Alan R. Liss, New York. 